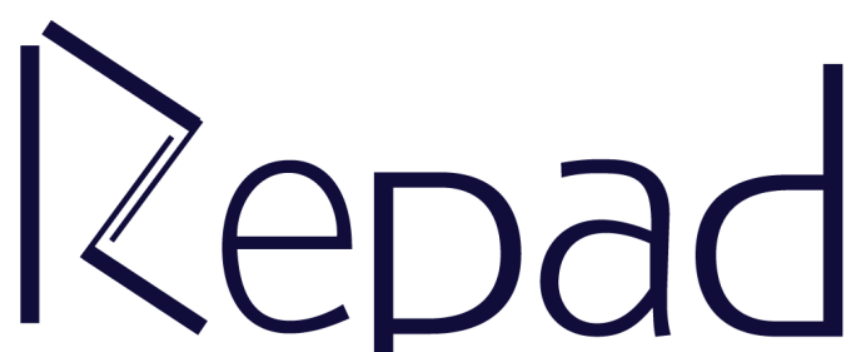

vol. 4, n. 1, Janeiro-Abril/2020

Revista Estudos e

Pesquisas em Administração

(c) (1) 


\title{
O CENÁRIO DA PESQUISA CIENTÍFICA NO IFMT A PARTIR DO FINANCIAMENTO À PESQUISA E DA PRODUÇÃO
}

\author{
Raul Tavares Cecatto \\ raulcctt@gmail.com \\ https://orcid.org/0000-0001-9310-0518 \\ Instituto Federal de Educação, Ciência e Tecnologia de Mato Grosso \\ Primavera do Leste, Mato Grosso, Brasil \\ Gabriella Zanoto Botton \\ https://orcid.org/0000-0001-9589-1202 \\ Instituto Federal de Educação, Ciência e Tecnologia de Mato Grosso \\ Primavera do Leste, Mato Grosso, Brasil \\ Laura Wobeto Burtet \\ https://orcid.org/0000-0002-6328-9580 \\ Instituto Federal de Educação, Ciência e Tecnologia de Mato Grosso \\ Primavera do Leste, Mato Grosso, Brasil \\ Diogo Barbosa Leite \\ http://orcid.org/0000-0002-8490-0502 \\ Instituto Federal de Educação, Ciência e Tecnologia de Mato Grosso \\ Primavera do Leste, Mato Grosso, Brasil \\ Silvana Santos da Cruz \\ https://orcid.org/0000-0001-5872-8916 \\ Instituto Federal de Educação, Ciência e Tecnologia de Mato Grosso \\ Cuiabá, Mato Grosso, Brasil
}

\begin{abstract}
Resumo
O desenvolvimento das Instituições de Ciência e Tecnologia passa necessariamente pelo debate quanto ao progresso da pesquisa e do impacto das produções realizadas pelos pesquisadores e pela academia. Partindo disso, este estudo teve por objetivo mapear a produção científica dos pesquisadores de uma instituição federal de ensino, especificamente o IFMT. Utilizando de coleta de dados secundários e métodos bibliométricos, o estudo levantou informações acerca da aplicação de recursos para financiamento da pesquisa científica na instituição, além de terem sido averiguadas as produções científicas dos projetos de pesquisa. Como resultados, foram apresentadas a produção bibliográfica de parte dos projetos de pesquisa, bem como relatos dos coordenadores acerca de desafios, sugestões e novos caminhos para a pesquisa na instituição.
\end{abstract}

Palavras-chave: Produção bibliográfica. Bibliometria. IFMT. 


\title{
SCIENTIFIC RESEARCH SCENARIO AT IFMT ACCORDING TO RESEARCH FINANCING AND THE TEACHER ACADEMIC PRODUCTION
}

\begin{abstract}
The development of the Science and Technology Institutions goes through the debate about the progress of research and the impact of the productions made by researchers and academia. Based on this, the goal of this study was to map the scientific production of researchers from a federal educational institution, the IFMT. Using secondary data collection and bibliometric methods, the study provides information on resource applications for funding scientific research in the institution, besides were evaluated the scientific productions of research projects. As results, were presented the bibliographic production of part of the research projects, as well as the reports of the coordinators about the challenges, suggestions and new ways for research in the institution.
\end{abstract}

Keywords: Bibliographic production. Bibliometry. IFMT.

Submetido: 16/12/2019

Aceito: 23/01/2020

Publicado: 31/01/2020

\section{Considerações iniciais}

As discussões acerca da quantidade e qualidade da pesquisa científica brasileira, alvo de diversos estudos, foram sendo desenvolvidas ao longo do tempo. O país tem experimentado um avanço na relevância das publicações brasileiras, principalmente pelo desenvolvimento de sua estrutura educacional, qualificação dos pesquisadores e pela maior disponibilização de recursos para financiamento da pesquisa. Contudo, ainda há um vasto caminho a ser percorrido, já que a nível global, o país ainda se mantém muito distante dos principais países que mais investem em pesquisa (SENADO FEDERAL, 2012).

A partir disso, faz-se necessário mapear a pesquisa nas instituições de ensino, visando estabelecer cenários para que sejam criadas discussões e políticas pertinentes para os seus maiores desafios. Por isso, este estudo amplia essas discussões no Instituto Federal de Educação, Ciência e Tecnologia de Mato Grosso (IFMT), tendo o objetivo de mapear a produção científica dos pesquisadores da instituição. Esse mapeamento foi operacionalizado a partir do levantamento de dados secundários referentes aos montantes utilizados para o financiamento da pesquisa na instituição, assim como a coleta de dados primários, mediante aplicação de questionário junto a coordenadores de projetos de pesquisa.

Nesse contexto, Audy (2017) discorre sobre o papel das instituições de ensino. Essas atuam como veículos de desenvolvimento social e econômico dentro de uma sociedade, ampliando o seu papel básico de ensino. Somado a isso, a pesquisa surge como impulso nesse processo de transformação, trazendo os resultados para a comunidade, atuando como fonte de resolução de problemas e servindo de base para novos produtos e serviços. Desta forma, o autor evidencia a relevância da conexão entre universidade e pesquisa.

Diante disso, mapear a pesquisa no IFMT se justifica perante sua relevância econômica, social e acadêmica. Conhecer e pesquisar a vocação das pesquisas 
realizadas pela instituição é um marco para o fortalecimento e avanço deste elemento como parte do tripé pesquisa, ensino e extensão, bem como para a gestão institucional. Além disso, é um importante ponto de partida para novos estudos, além de permitir futuras pesquisas na própria Instituição de Ciência e Tecnologia (ICT), como também comparações com relação a outras.

\section{Referencial Teórico}

O termo Ciência vem do verbo latim Scire, que significa "conhecer", "aprender". Porém, essa definição é insuficiente para diferenciar ciência de outras atividades que também envolvem o conhecimento e o aprendizado. Conforme Prodanov e Freitas, (2013), ciência é um conjunto de atividades e atitudes racionais, dirigida a um conhecimento com objetivo limitado, possível de ser submetida a uma verificação. Ciência é "conjunto de proposições, relacionados logicamente, sobre o comportamento de um certo fenômeno que se deseja estudar" (LAKATOS; MARCONI, 2017, p. 80)

Segundo Prodanov e Freitas (2013), o objetivo principal da ciência é chegar à veracidade dos fatos. A diferença entre o conhecimento científico e os outros tipos de conhecimento é que o conhecimento científico tem uma fundamentação e uma metodologia a serem seguidos, além de ser baseada em informações que disponibilizam explicações a respeito do objeto estudado, submetidas a verificação. Já conforme Freitas e Sobral, (2014), a metodologia científica busca resgatar a capacidade de pensar dos alunos, passando de um nível espontâneo para um nível reflexível, na qual dessa forme que se aprende a pensar à medida que se realizam as indagações sobre o ato de pensar.

Prodanov e Freitas (2013) afirmam que o conhecimento científico é dotado de algumas características, como o acumulativo, útil para melhorar a vida humana, analítico, comunicável e preditivo. Os autores argumentam ainda que pesquisa científica tem por finalidade conhecer cientificamente aspectos de determinado assunto, portanto, deve ser sistemática, metódica e crítica. Na academia, a pesquisa é tida como um exercício que desperta o espírito da investigação diante dos problemas sugeridos pelos professores.

Os mesmos autores também reforçam que a pesquisa cientifica é um estudo planejado, no qual é o meio de abordagem do problema que o caracteriza como científico. Tem por objetivo descobrir respostas para questões de acordo com a aplicação de um método científico. A pesquisa cientifica parte de um problema que o conhecimento disponível não é capaz de responder, e para encontrar a solução desse problema são levantadas algumas hipóteses, que serão confirmadas ou recusadas pela pesquisa. Para eles, o planejamento da pesquisa depende tanto do problema, da sua natureza e da situação espaço-temporal, quanto da natureza e grau de conhecimento do pesquisador.

De acordo com Mascarenhas, Zambaldi e Moraes (2011), um artigo científico seria relevante conforme sua capacidade de gerar novos entendimentos, de atrair a atenção da audiência na comunidade, ou de criticar e contestar suposições anteriores. A produção de uma pesquisa cientifica com excelência depende da idealização do rigor e da relevância do texto científico, causando impacto na comunidade, sendo essa uma condição necessária para publicação em periódicos prestigiados. Quem atribui relevância a um trabalho são os membros da comunidade, já que o texto deve dialogar com suas tendências, provando ser útil à definição de suas realidades, exigindo assim maior comprometimento do pesquisador. 
Dentre os pontos cruciais para o desenvolvimento da pesquisa nas ICT contam os grupos e o os projetos de pesquisa. Nesse caso, a importância de grupos de pesquisa na Rede Federal de ensino, do qual o IFMT é parte, é antiga. Remonta da década de 1980, com o surgimento do primeiro grupo de pesquisa de toda a rede. Com o passar do tempo, a disposição dos grupos de pesquisa se modificou, sobretudo a partir da expansão da Rede Federal e da criação dos Institutos Federais. No ano base de 2016, foram catalogados 2.749 grupos de pesquisa em todas as instituições da Rede Federal, com um total de 19.996 pesquisadores, sendo ao todo 37.953 membros, dentre pesquisadores, técnicos, estudantes e colaboradores (ESTEVAM, 2017).

Tendo isso, mapear a produção, características, dentre outros aspectos próprios dos grupos e projetos de pesquisa do IFMT pode ser um importante feito a fim de demarcar cenários e estratégias de fortalecimento, o que justifica a pertinência deste estudo. O avanço da Rede Federal de Ensino Profissional acarretou, dentre outras coisas, o incremento na participação da pesquisa realizada nas instituições membras. Nesse caso, os grupos de pesquisa são importantes mecanismos de propagação da pesquisa, já que pesquisadores de diferentes ou semelhantes áreas se agrupam com finalidades e interesses de pesquisas comuns. Logo, os grupos de pesquisa têm se firmado como uma importante estratégia para evolução da pesquisa científica de maior impacto e de resultados com maior relevância, inclusive dentro do Instituto Federal de Educação, Ciência e Tecnologia de Mato Grosso.

\section{Procedimentos metodológicos}

O objetivo do estudo foi de natureza descritiva (GIL, 2002), sintetizado por descrever os fenômenos observados e suas interações. Logo, descritiva porque a pesquisa realizou, a partir do recorte temporal, o mapeamento da produção docente na instituição em variados estratos de interpretação. Os resultados da pesquisa expressamse pela abordagem quantitativa (CRESWELL, 2007), a partir das informações de natureza bibliométrica, com dados consolidados acerca da produção dos projetos de pesquisa analisados.

A partir do levantamento bibliográfico, foi realizada análise de dados secundários que permitiu extrair informações da evolução do financiamento para a pesquisa na instituição. Além disso, foi desenvolvido a partir do levantamento de dados primários, mediante aplicação de questionários. A fim de operacionalizar a investigação, ela foi dividida em linhas de atuação, conforme Figura 1.

Figura 1. Linhas para realização da pesquisa

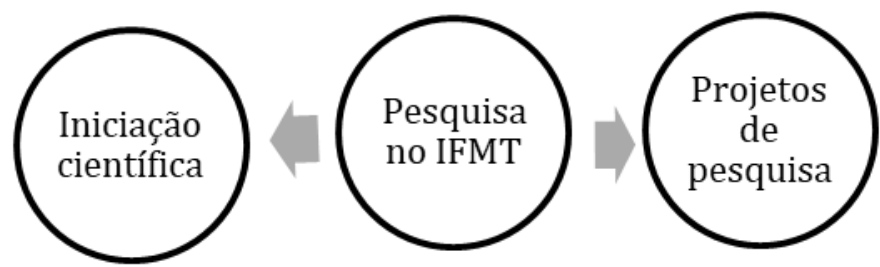

Fonte. elaborado pelos autores (2019).

Desse modo, a pesquisa se consistuiu em duas linhas complementares:

a) Iniciação científica no IFMT: teve como objetivo pesquisar a composição dos recursos financeiros destinados a iniciação científica no IFMT e a sua evolução nos últimos anos. 
b) Projetos de pesquisa: buscou-se realizar um levantamento de informações básicas sobre a produção e perspectivas dos projetos de pesquisa aprovados em editais internos da instituição e que tenham sido encerrados entre janeiro de 2017 e julho de 2019.

Na próxima seção, dividida de acordo com as linhas de pesquisa executadas ao longo do estudo, serão apresentados os resultados gerais de cada uma delas. A linha de pesquisa acerca da produção bibliográfica dos projetos de pesquisa da instituição é aquela cujos resultados aparecem mais densamente discutidos neste trabalho. Informações gerais, além de considerações metodológicas estão apresentadas nas respectivas subdivisões.

\section{Resultados e Discussão}

\subsection{A evolução da iniciação científica na instituição}

A partir da coleta de informações junto a Pró-Reitoria de Pesquisa, PósGraduação e Inovação (PROPES) do IFMT, foi realizada uma análise descritiva a respeito da composição financeira do programa de iniciação científica do IFMT, a partir da evolução das bolsas e da evolução do financiamento da iniciação científica (IC). Os dados foram coletados durante os meses de agosto e setembro de 2018 , de forma que fossem informações já consolidadas e por isso, com maior grau de representatividade.

O IFMT, a partir do uso de recursos próprios, possui dois tipos de bolsas: o Programa de Iniciação Cientifica dos cursos técnicos (PROIC-TEC) e o programa para estudantes de graduação (PROIC-GR). O financiamento externo é dado por duas agências de fomento à pesquisa, em quatro modalidades diferentes: a Iniciação Cientifica da Fundação de Amparo à Pesquisa do Estado de Mato Grosso (ICFAPEMAT); o Programa Institucional de Bolsas de Iniciação em Desenvolvimento Tecnológico e Inovação (PIBITI-CNPq), pelo Programa Institucional de Bolsas de Iniciação Científica (PIBIC/CNPq) e o Programa Institucional de Bolsas de Iniciação Científica - Ensino Médio (PIBIC-EM/CNPq).

A fim de estabelecer um padrão para visualização dos resultados, foram construídas tabelas e, partir delas, foram gerados gráficos de linha, mais adequados para estabelecimento de um padrão de evolução ao longo do tempo. A Figura 2 estabelece a evolução no número de bolsas a partir do biênio de 2009/2010 na instituição.

Figura 2. Evolução na oferta de bolsas por modalidade

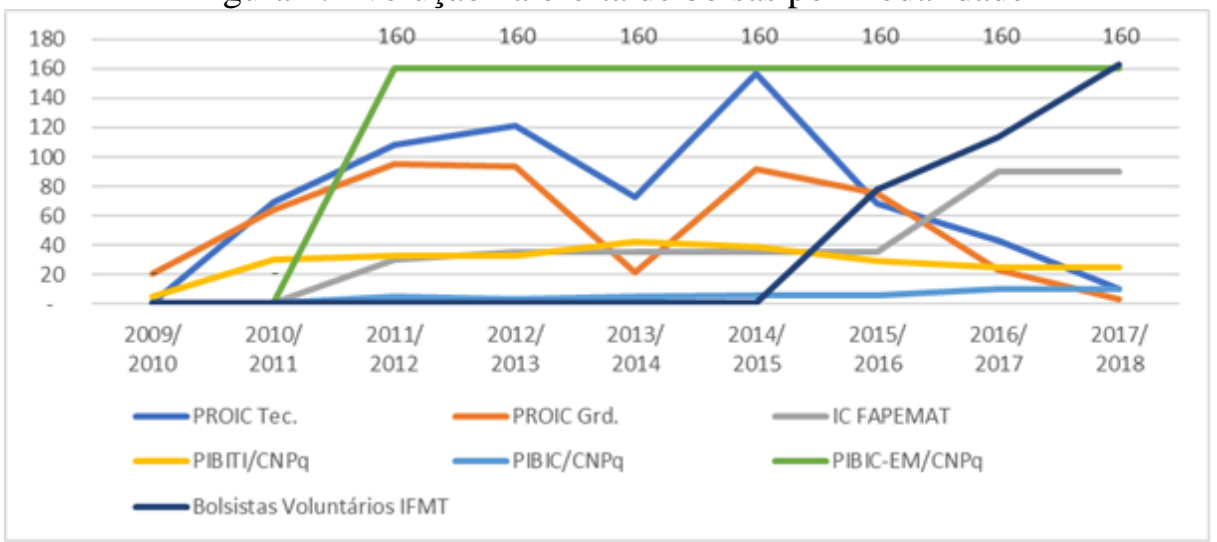

Fonte. dados da pesquisa (2019) 
A partir dos resultados, nota-se um primeiro aspecto relevante que é o crescimento de pesquisadores voluntários. A pesquisa voluntária é atrativa por ser não onerosa em recursos e por isso pode ser um importante canal de solução quando verificam-se cenários de escassez ou desinvestimento em pesquisa. A Figura 3 apresenta a evolução na oferta de bolsas por fonte.

A partir dos resultados, observa-se que há uma prevalência do financiamento externo em detrimento do interno, o que pode ser explicado de algum modo pela maior disponibilidade de recursos. Outra análise realizada a partir dos resultados obtidos foi acerca do financiamento, seja por modalidade ou por fonte, conforme destacado na Figura 4.

Figura 3. Evolução na oferta de bolsas por fonte

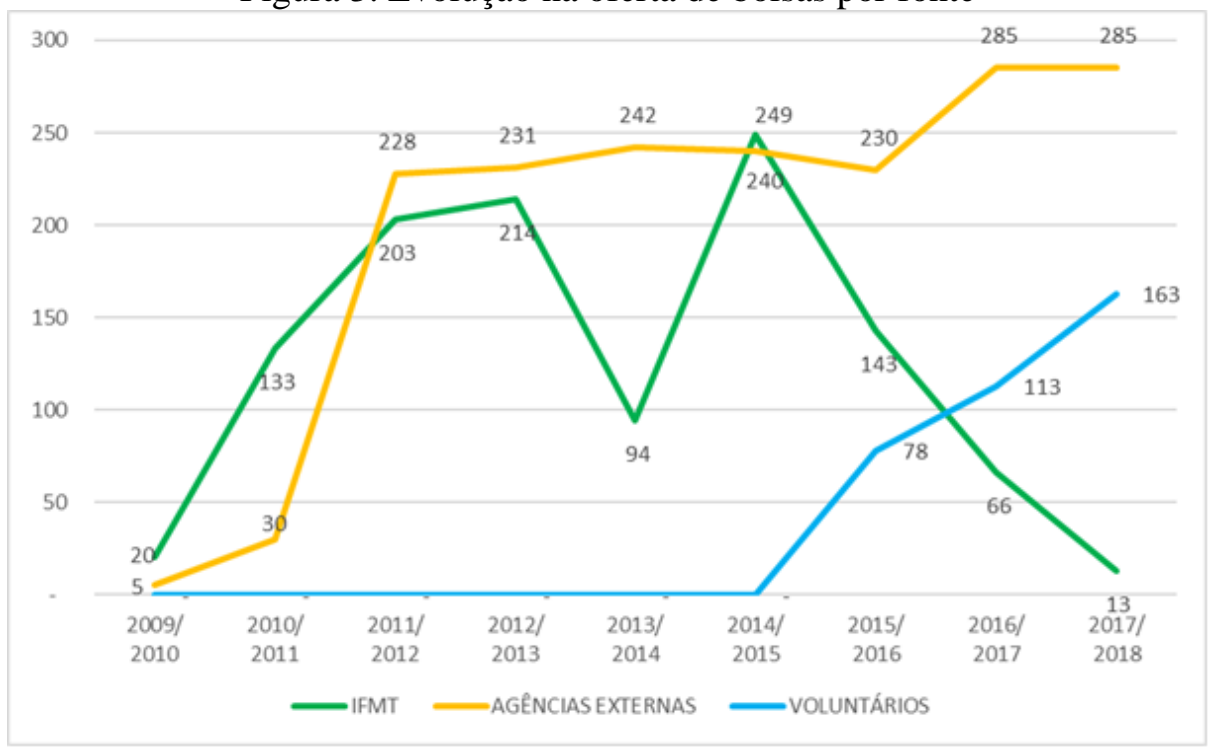

Fonte. dados da pesquisa, (2019)

Figura 4 - Evolução na oferta de financiamento por modalidade

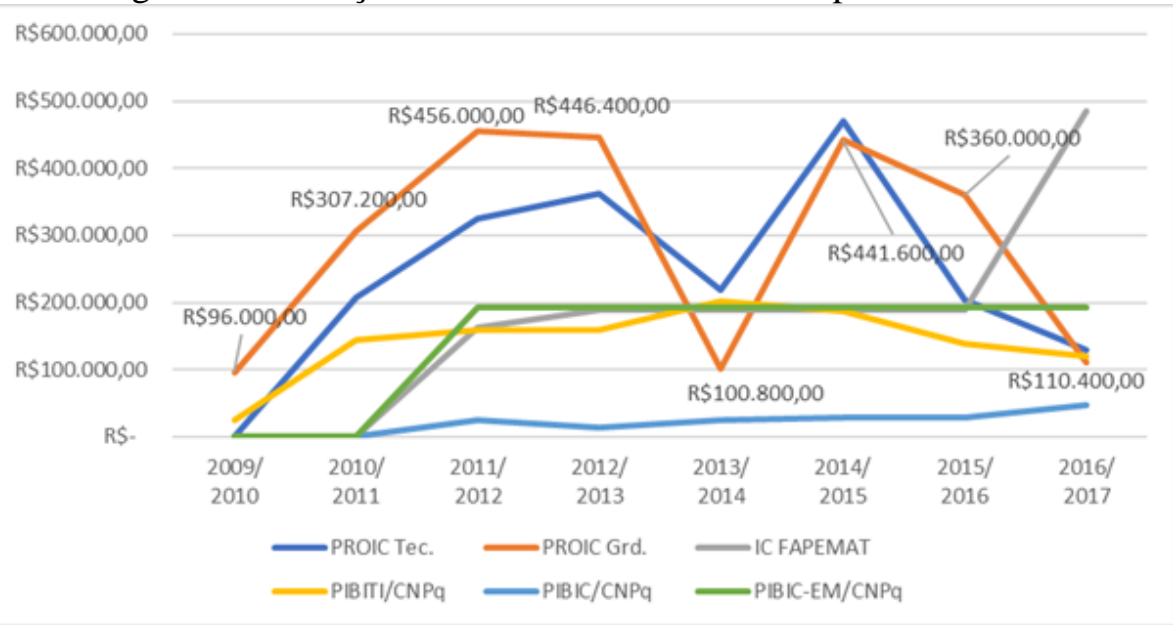

Fonte. dados da pesquisa (2019)

Em relação a primeira modalidade, PROIC-TEC, nota-se certa variação no montante investido. Em relação a modalidade PROIC-Grd. verifica-se a mesma 
tendência da modalidade técnica, com a principal diferença sendo a maior proporção de recursos investidos, na série histórica. A partir de 2009, tendência positiva, sendo sucedida por uma tendência de queda a partir de 2014.

$\mathrm{Na}$ modalidade IC-FAPEMAT, observa-se uma tendência positiva, sendo crescente o montante investido. Isso sugere, além da maior disponibilidade de recursos pela agência, a criação de redes de cooperação externa, de modo que sejam supridas as necessidades da instituição, inclusive substituindo as fontes de financiamento internas.

$\mathrm{Na}$ próxima, PIBITI/CNPq, verificou-se uma estabilidade ao longo da série histórica, sendo disponibilizados em 2016 cerca de $\mathrm{R} \$ 110$ mil. Já na modalidade $\mathrm{PIBIC/CNPq}$, percebe-se ainda uma pequena parcela de participação na IC da instituição, sendo também um investimento considerado constante ao longo do período analisado, sem picos nem quedas relevantes.

Por fim, na modalidade PIBIC-EM/CNPq, verifica-se uma relevância na participação de recursos, que foi crescente no início do período analisado e prosseguiu com estabilização. Embora não seja responsável pelo maior valor investido, é essa a modalidade que concentra o maior número de bolsas. Isso pode ser explicado pelas peculiaridades de cada edital de oferta, que disponibilizam bolsas, custeio, equipamento e linhas de financiamento diferentes.

A fim de comparar o financiamento por fontes, interna ou externa, foi realizado um gráfico, conforme disposto na Figura 5.

Figura 5. Evolução na oferta de financiamento por fonte

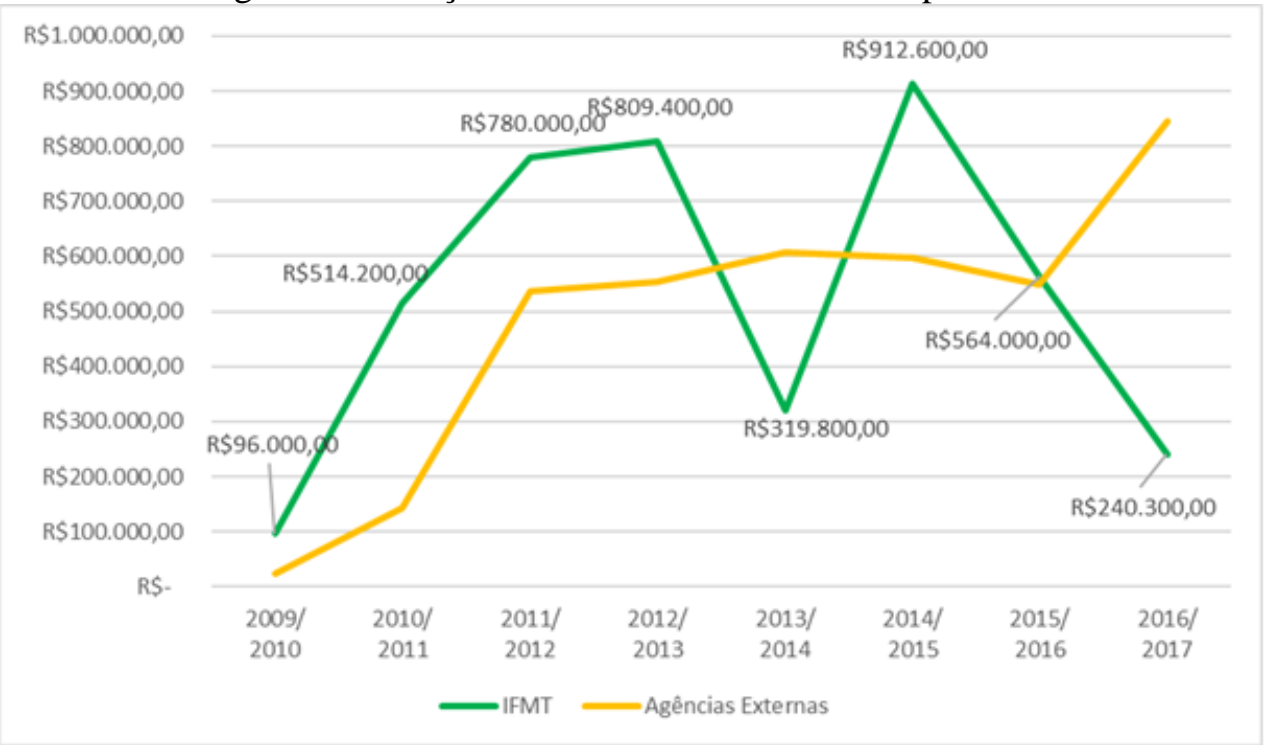

Fonte. dados da pesquisa (2019)

A análise da figura implica afirmar que no início da implementação dos programas de IC, a fonte de financiamento principal para o programa era originária de recursos próprios. Contudo, passado o tempo e a evolução do programa, foram sendo implementados recursos de origem externa, até que no ano de 2015 foram superiores as fontes internas pela primeira vez. Em 2016, os recursos para financiamento em IC originados de fontes internas foram da ordem de $\mathrm{R} \$ 240$ mil reais, enquanto de fontes externas foram de $\mathrm{R} \$ 846$ mil. 


\subsection{A produção bibliográfica dos projetos de pesquisa}

Por fim, a segunda linha do projeto consistiu no mapeamento da produção bibliográfica dos projetos de pesquisa do IFMT. A sondagem foi realizada por meio da aplicação de um formulário online desenvolvido via Google Forms. O formulário continha perguntas fechadas e abertas, por exemplo para a especificação das produções dos projetos de pesquisa e considerações a serem evidenciadas. Tal sondagem ocorreu entre os dias 03 e 22 do mês de julho de 2019, tendo em vista que era a etapa final para realização do projeto de pesquisa homônimo, realizado na instituição. Foram obtidas 43 respostas de um total de 245 projetos, após sucessivos contatos realizados via email, único canal escolhido para acesso aos coordenadores. Foram contactados coordenadores de projetos de pesquisa, vinculados a editais da PROPES ou a editais internos dos campi, que tenham sido encerrados entre janeiro de 2017 e julho de 2019.

Ao término deste prazo, as informações foram tratadas e agrupadas para que desta maneira pudessem ser transformadas em dados com cunho quantitativo, destacadas a seguir.

A Figura 6 contém os projetos de pesquisa e seus respectivos campi que responderam ao questionário aplicado. Pode-se observar que o campus com maior participação foi o Octayde Jorge da Silva, da cidade Cuiabá. O segundo lugar foi o campus da cidade de Campo Novo do Parecis. Pode-se observar também uma alta distribuição em relação às demais respostas.

Figura 6. Origem dos coordenadores de projetos

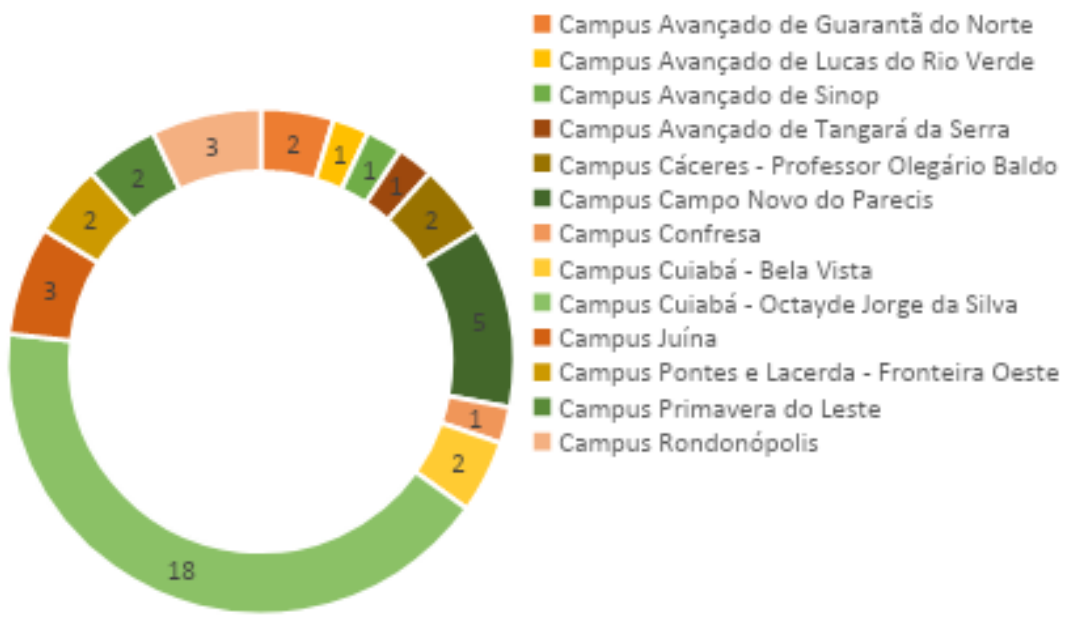

Fonte. dados da pesquisa (2019)

Os projetos de pesquisa contam com alguns tipos de financiamento para o seu desenvolvimento, conforme Figura 7. O gráfico abrange tais dispositivos, sendo possível constatar que mais de $50 \%$ dos recursos são provindos dos recursos próprios da instituição $(54,5 \%)$, outros projetos contam com financiamentos da FAPEMAT (27,3\%), CNPq (4,5\%), e por último os projetos que não apresentam financiamento por serem relacionados a iniciativas voluntárias $(13,6 \%)$.

Os projetos de pesquisa podem ou não contar alunos que participam em seu desenvolvimento com auxílio de bolsas. A Figura 8 mostra que mais da metade, 59,1\% dos projetos possuem 1 aluno bolsista, cerca de 13,6\% possuem 2 alunos bolsistas, 
18,2\% possuem mais de 2 alunos bolsistas e cerca de 9,1\% de projetos sem alunos bolsistas.

Os projetos de pesquisa também podem contar com coordenadores bolsistas. Foi verificado que dos projetos analisados, 24 possuem coordenadores com bolsa e cerca de $56,8 \%$ não possui coordenadores bolsistas. Sabe-se que os projetos de pesquisas contam com o auxílio da taxa de bancada, onde tal subsídio é direcionado para a ajuda financeira no desenvolvimento do projeto e compra de alguns tipos itens necessários para a execução. A partir das respostas, observou-se que 36 projetos dependiam de tal recurso.

Figura 7. Tipo de financiamento dos projetos

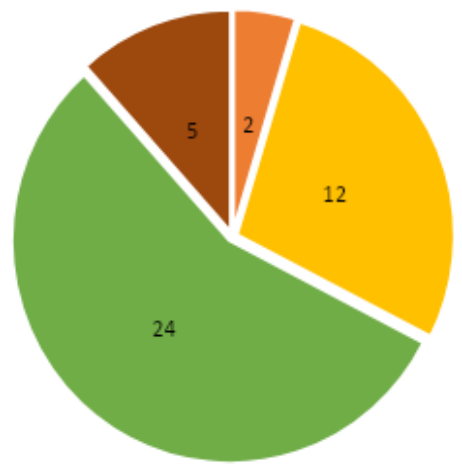

a CNPq EAPEMAT IIFMT-recursos próprios Sem financiamento

Fonte. dados da pesquisa (2019)

Figura 8. Alunos bolsista por projeto

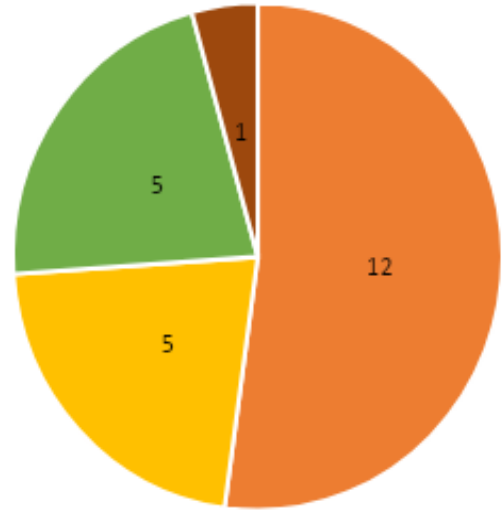

aluno 2 Alunos Mais de 2 Sem aluno bolsista

Fonte. dados da pesquisa (2019)

A Figura 9 apresenta os resultados acerca do quantitativo de projetos por grau de satisfação com a execução, marcados pelos respectivos coordenadores. A análise da Figura 9 permite interpretar que a maioria dos projetos têm uma execução positiva e pouquíssimos tiveram problemas com a sua execução. Isso é positivo para a instituição, já que foi obtido sucesso na maioria das execuções dos projetos.

Foi solicitado que os coordenadores justificassem, em uma questão aberta, os motivos pelos quais avaliavam o grau de satisfação em relação a execução dos 
trabalhos. Em geral, as respostas afirmaram satisfação, pois atingiram metas e prazos, gerando assim bons resultados das pesquisas, já que em sua maioria houve a participação e colaboração direta e eficiente de seus integrantes.

Foi indagado aos respondentes que também marcassem o grau de satisfação com os resultados do projeto, o que permitiu verificar que nenhum dos projetos participantes obteve resultado insatisfatório ou muito insatisfatório. Os principais motivos relacionados ao índice de satisfação foram a percepção dos coordenadores perante a participação dos alunos nas pesquisas e em eventos, já que desta maneira houve uma maior interação e aprendizagem entre o meio acadêmico e social.

Figura 9. Grau de satisfação com a execução do projeto

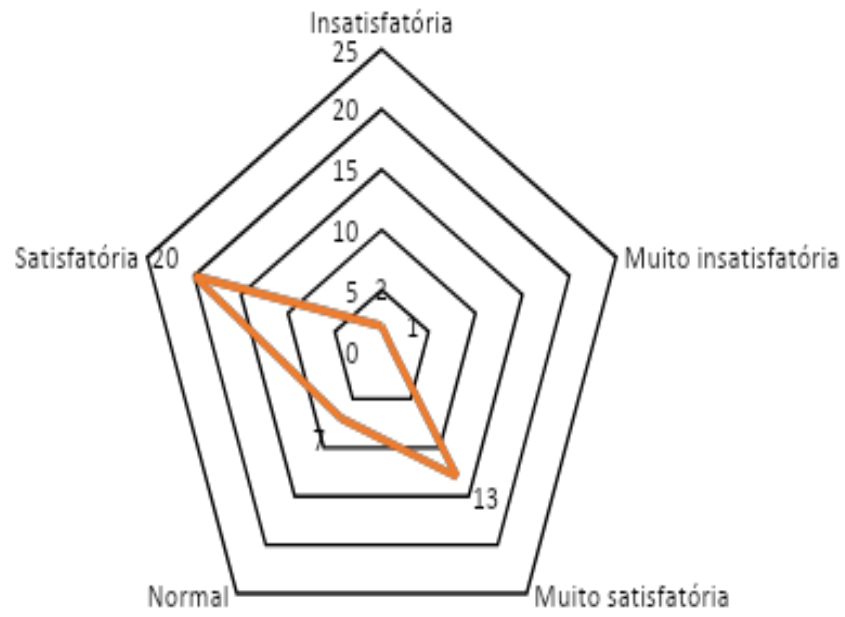

Fonte. dados da pesquisa (2019)

Solicitou-se que fossem apresentadas as principais dificuldades relacionadas com a execução do projeto. Entre as principais dificuldades, foram citadas:

a) a falta de infraestrutura física: como indicado pelos coordenadores, faltam espaços para realizar reuniões e laboratórios específicos;

b) o aumento do prazo dos projetos: muitos coordenadores indicaram que devido a carga horária de aula não tiveram o tempo para dedicar-se à pesquisa no prazo estipulado em edital;

c) falta de recursos para aquisição de materiais: um exemplo apresentado foi a dificuldade de encontrar instituições com equipamento adequado para realizar ensaios de condutividade térmica, implicando em tempos mais longo;

d) carga horária dos membros: causaram certa dificuldade para os grupos, já que existiu dificuldade em ter os encontros com a equipe, uma vez que os estudantes têm alta carga horária em sala de aula/estágio;

e) burocracia excessiva com levantamento de orçamentos e prestações de conta: segundo os coordenadores, tomam tempo do pesquisador quando comparado ao tempo que investe na própria pesquisa.

Por fim, foi solicitado que os coordenadores apresentassem sugestões de melhorias para o desenvolvimento do eixo Pesquisa na instituição. O Quadro 1 apresenta o agrupamento das sugestões mais recorrentes.

Quadro 1. Sugestões para desenvolvimento do Eixo Pesquisa no IFMT 


\begin{tabular}{|c|c|}
\hline Financiamento & $\begin{array}{l}\text { - Regular prazos para pagamentos de bolsa } \\
\text { - Aumento da taxa de bancada } \\
\text { - Aumento dos recursos destinados a pesquisa } \\
\text { - Maior participação em eventos } \\
\text { - Apoio financeiro para publicação dos trabalhos e investimento }\end{array}$ \\
\hline Espaço & $\begin{array}{l}\text { - Envolver a comunidade externa } \\
\text { - Divulgação dos resultados de pesquisas } \\
\text { - Identificar os pesquisadores que trabalham linhas de pesquisa } \\
\text { semelhantes a fim de formar grupos de pesquisa mais fortes } \\
\text { - Parceria com outras ICT } \\
\text { - Implementar laboratórios para pesquisa }\end{array}$ \\
\hline Edital & $\begin{array}{l}\text { - Aliar aos PPCs } \\
\text { - Articulação com ensino } \\
\text { - Diminuir burocracia para processos de compras } \\
\text { - Consistência e uniformidades nos editais } \\
\text { - Uso de prazo de } 18 \text { meses }\end{array}$ \\
\hline Carreira & $\begin{array}{l}\text { - TAE's na coordenação de projetos de pesquisa } \\
\text { - Valorização dos pesquisadores } \\
\text { - Normatizar a participação de alunos egresso e profissionais da educação } \\
\text { inativos } \\
\text { - Redução carga horária de aula } \\
\end{array}$ \\
\hline
\end{tabular}

Fonte: dados da pesquisa, (2019)

Em relação a produção bibliográfica dos projetos, foi solicitada a apresentação de todas as publicações realizadas e a Tabela 1 sintetiza os principais resultados obtidos.

Tabela 1. Tipo de Produções realizadas

\begin{tabular}{|c|c|c|}
\hline Tipo & Título & Número \\
\hline \multirow{19}{*}{$\begin{array}{c}\text { Publicação em } \\
\text { anais de } \\
\text { evento ou } \\
\text { congresso }\end{array}$} & $10^{\circ}$ CATI - UNEMAT - Barra do Bugres & 1 \\
\hline & Anais da IV JENPEX IFMT Tangará da Serra & 4 \\
\hline & Anais da JENPEX IFMT Campus Cuiabá 2017 & 2 \\
\hline & $61^{\circ}$ CONGRESSO BRASILEIRO DO CONCRETO - BC2019 & 1 \\
\hline & CEPEX III IFMT Rondonópolis 2019 & 2 \\
\hline & CITCEM/SPAE | Faculdade de Letras da UP & 4 \\
\hline & CITCEM/SPAE Descobrindo & 1 \\
\hline & Colóquio Internacional "Modos de Fazer" & 5 \\
\hline & CONECTA IF- VII Semana de Produção Científica do IFB & 1 \\
\hline & Flisol2019 & 1 \\
\hline & IFMT CAMPUS JUÍNA & 4 \\
\hline & II manhã de Campo do IFMT CNP & 1 \\
\hline & III JENPEX Campus Avançado Sinop & 1 \\
\hline & IV SECITA & 1 \\
\hline & Anais da JENPEX de 2018 IFMT Campo Novo do Parecis & 2 \\
\hline & Revista Digoreste & 1 \\
\hline & SEMIEDU 2018 & 1 \\
\hline & SEMIEDU 2017 & 1 \\
\hline & SIGET - 2019 & 1 \\
\hline
\end{tabular}




\begin{tabular}{clcc}
\hline & VIII SIMCOPE & & 1 \\
\hline & \multicolumn{1}{c}{ TÍTULO DA REVISTA } & QUALIS & \\
& Revista Biodiversidade & C & 1 \\
Publicação em & Revista Educação, Cultura e Sociedade & B4 & 1 \\
periódico & Revista de Estudos Acadêmicos de Letras & B3 & 1 \\
& Revista Athena & B5 & 1 \\
& Revista Africa(s) & B3 & 1 \\
& Brazilian Journal of Development & B2 & 1 \\
\hline
\end{tabular}

Fonte. dados da pesquisa (2019)

A partir da Tabela 1, pode-se afirmar que há uma maior atuação dos projetos de pesquisa em anais de eventos ou em congressos, do que em periódicos. Com relação aos periódicos, a publicação com maior impacto ocorreu no "Brazilian Journal of Development", que possui Qualis B2. Diante disto, infere-se que apenas 6 projetos de pesquisa, diante de um total de 43 respondentes, tiveram a recorrente publicação.

Os projetos de pesquisa ao longo de sua duração produzem e desenvolvem inúmeras produções bibliográficas. Nos projetos em estudo, como evidenciado na Figura 10, foram apontados "artigos completos e publicados", "livros e capítulos", além de "trabalhos publicados em anais de congressos". Há ausência de projetos que produziram "partitura musical" e "traduções", além de que foram contabilizados vinte produções como sendo "outras produções bibliográficas".

Figura 10. Quantitativo das produções bibliográficas realizadas

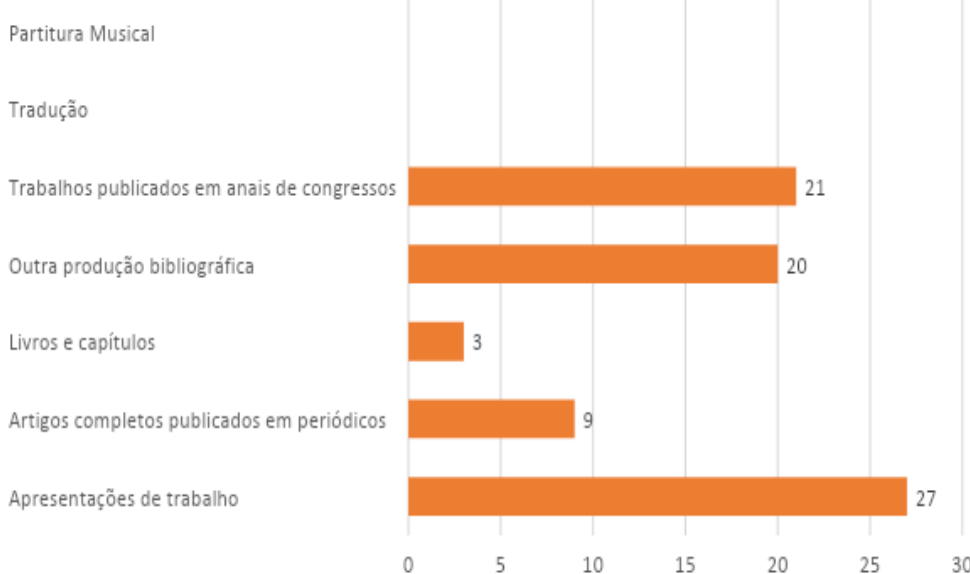

Fonte. dados da pesquisa (2019).

\section{Considerações finais}

Infere-se que há uma grande e vasta rede de conhecimento a ser catalogada, quantificada e divulgada para a comunidade interna e externa ao IFMT. Nota-se que o potencial de crescimento e desenvolvimento educacional a partir dos grupos e projetos de pesquisa é genuína e promissora, pois através do emprego de tais estratégias pode-se existir maior desenvoltura e abrangência na formação curricular, crescimento no caráter individual e uma ampliação de horizontes voltadas para as áreas de atuação dos discentes. 
Observa -se também que os projetos de pesquisa afloram as barreiras geográficas e expandem seus saberes por meio de congressos e eventos. A primeira linha de investigação obteve um panorama do investimento em pesquisa na primeira década da instituição, em que se pode constatar que o número de pesquisadores voluntários vêm aumentando. Outro aspecto apresentado foi que a maior parte das bolsas oferecidas no IFMT provém de financiamento externo. Na outra frente de pesquisa visualizou-se, ainda que com limitações de amostra, importantes sugestões e caminhos futuros a serem almejados para promoção do desenvolvimento da Pesquisa na instituição. Em relação as limitações do estudo, a própria natureza da investigação impôs restrições, principalmente quanto ao acesso dos coordenadores de projetos, dada a magnitude e a alta capilaridade dos campi do instituto federal pelo estado.

O estudo, parte dos resultados de um projeto executado na própria instituição, propôs oferecer novas constatações a partir das análises realizadas, servindo para mapear o cenário da pesquisa no IFMT, o que pode servir para o surgimento de iniciativas que garantam alto desempenho no uso dos recursos, além de oportunidades para melhorias. Pesquisas futuras podem ter o estudo como base para novas análises e discussão sobre os pontos essenciais para o desenvolvimento da Pesquisa na instituição, fortalecendo a comunidade, pesquisadores, docentes, grupos de pesquisa e seus projetos.

\section{Referências}

AUDY, J. A inovação, o desenvolvimento e o papel da Universidade. Estudos avançados, vol.31 no.90, São Paulo, 2017.

CRESWELL, J. W. Projeto de pesquisa: Métodos qualitativo, quantitativo e misto. 2. ed. Porto Alegre: ART MED Editoria S.A, 2007.

ESTEVAM, M. Os grupos de pesquisa na Rede Federal. In SOUZA, R. R. (Org.) Pesquisa, pós-graduação e inovação da Rede Federal de Educação Profissional, Científica e Tecnológica. Goiânia: IFG, 2017.

FREITAS, M. A. B; SOBRAL, A. V. C. Metodologia científica no curso de Administração: uma nova perspectiva didática. Revista Gestão em Análise, [S.1.], v. 3, n. $1 / 2$, p. 93-103, abr. 2016. ISSN 2359-618X. Disponível em: <doi:http://dx.doi.org/10.12662/2359-618xregea.v3i1/2.p93-103.2014>.

GIL, A. C. Como elaborar projetos de pesquisa. 4. ed. São Paulo: Atlas S.A, 2002.

LAKATOS, E. M.; MARCONI, M. A. Metodologia científica. São Paulo: Atlas, 2017.

MASCARENHAS, A. O.; ZAMBALDI, F.; MORAES, E. A. Rigor, Relevância e Desafios da Academia em Administração: Tensões Entre Pesquisa e Formação Profissional. Revista Administração de Empresas, v. 51, n. 3, p. 265-279, São Paulo, maio/jun. 2011 
PRODANOV, C. C.; FREITAS, E. C. Metodologia do Trabalho Científico: Métodos e Técnicas da Pesquisa e do Trabalho Acadêmico. Universidade Feevale: Novo Hamburgo, 2013.

SENADO FEDERAL. Brasil ainda longe dos líderes. Em discussão! Revista de audiências públicas do Senado Federal. Ano 3, N 12, setembro de 2012 